\title{
Como professores em formação continuada mobilizam saberes sobre escrita e avaliação de texto ${ }^{1}$
}

Maria Augusta G. de M. Reinaldo

Universidade Federal de Campina Grande

Este artigo tem por objetivo refletir sobre a relação teoria-prática na formação continuada do professor de língua materna. Enfoca-se a mobilização de saberes sobre escrita e avaliação de texto por três sujeitos, em uma atividade de prática de avaliação de texto, aplicada após a apresentação e discussão das teorias lingüísticas contemporâneas sobre o tema. Os resultados da análise mostram duas posições dos sujeitos, em termos de efeito do saber teórico recém-adquirido sobre a prática de avaliação de texto: um deles preferiu a situação de estabilidade, com uma avaliação centrada nos aspectos normativos da escrita; e dois apresentaram uma situação de transição, com inserção de critérios de avaliação de base textual.

This paper aims at reflecting on the theoretical-practical relation in the ongoing formation of the teacher of first language. It focuses on the mobilization of knowledge about writing and evaluation of texts by three subjects, in a practicing activity of text evaluation, applied after the presentation and discussion of contemporary linguistic theories about the theme. The analyzed results show two positions of the subjects, concerning the effect of theoretical knowledge just-acquired about the practicing of text evaluation: one of them preferred the established situation, with an evaluation centered on the normative aspects of writing; and the other two showed a transitional situation, with the introduction of criteria of textual-base evaluation.

\section{Introdução}

Os estudos sobre o ensino de produção de texto, no contexto brasileiro, têm mostrado que a tradição escolar de avaliação de texto escrito se fundamenta em critérios apenas lingüísticos, sem qualquer articulação com as condições de produção do texto objeto de avaliação.

\footnotetext{
${ }^{1}$ Este trabalho faz parte da pesquisa Práticas de Escrita e de Reflexão sobre a Escrita em Contextos de Ensino, projeto integrado CNPq/UNICAMP/UFCG (proc. 520427/2002-5).
} 
A principal conseqüência dessa prática tem sido a promoção dos alunos pela capacidade de escrever redações corretas do ponto de vista ortográfico e gramatical, e não necessariamente pela competência de produzir textos coesos e coerentes, critérios advindos das contribuições das ciências da linguagem, em particular das teorias sobre texto e discurso (GERALDI, 1984 e 1993; VAL, 1993; EVANGELISTA et alii,1998).

Nesse quadro, a produção de conhecimento acerca dos procedimentos de avaliação da escrita escolar se apresenta como um tema relevante, dada a sua relação com a formação do professor de língua materna. Não se pode deixar de ter presente que o domínio de novos conceitos lingüísticos e sua utilização em práticas de ensino inovadoras representam situações bastante desafiadoras para os professores atuantes na educação básica, quando sua formação e experiência de ensino foram calcados em uma perspectiva teórica tradicional de língua. Esse tema tem mobilizado não apenas os profissionais da educação e de áreas específicas como a Lingüística Aplicada, mas também o poder público, com a instituição de programas destinados à formação continuada desse profissional.

Neste trabalho, pretendemos refletir sobre a relação teoria/prática, no âmbito de um contexto de formação continuada, considerando as seguintes variáveis: a) o saber sobre escrita e avaliação de texto, segundo os estudos lingüísticos contemporâneos, disponibilizado a professores nas disciplinas de um curso de especialização; e b) o saber sobre escrita e avaliação de texto da/ na prática desses professores.

Em função dessas variáveis, este artigo procura contemplar inicialmente a questão da relação entre as formas do saber docente e os modelos de formação de professor. Em seguida, traça a evolução, no campo dos estudos lingüísticos e educacionais, dos conceitos de escrita e avaliação, que constituem saberes objeto da formação do professor de língua materna. Por fim, são analisados os saberes mobilizados por três professoras numa atividade de avaliação de texto escolar, realizada no contexto de formação continuada já referido.

\section{Os saberes docentes e sua relação com os modelos de formação de professor}

A concepção do ato de ensinar como um processo que envolve a mobilização de saberes de diversas ordens trouxe à tona, nos recentes 
estudos sobre formação de professores, a questão do saber e de sua produção. Defende-se, nesse processo, o estudo, de forma não normativa, do conjunto dos saberes mobilizados e utilizados pelos professores em suas tarefas, entendendo-se saber como o conjunto dos conhecimentos, competências, habilidades e atitudes, incorporados no processo de trabalho docente (PERRENOUD, 2002; TARDIF, 2002). Evocamos, com base em Carvalho e Perez (2002), o que tem sido considerado na bibliografia da área como saberes necessários para o saber fazer do professor de um conteúdo específico: os saberes conceituais e metodológicos e os saberes integradores.

Os saberes conceituais e metodológicos estão relacionados com o conhecimento da matéria objeto de ensino, e envolvem alguns requisitos, como o conhecimento dos problemas que originaram a construção de determinados saberes na área e sua articulação de forma coerente, de modo a evitar visões estáticas e dogmáticas, deformadoras da natureza do conhecimento; o conhecimento das orientações metodológicas adotadas na construção dos saberes da área; o conhecimento, de alguma forma, dos desenvolvimentos científicos recentes e suas perspectivas.

Falar do saber conceitual e metodológico, como componente da formação do professor de língua materna significa falar de um saber relativo ao fato lingüístico, oral ou escrito, considerado nas dimensões estrutural, semântica, interacional, discursiva e histórica. Impõe-se aqui oferecer ao professor em formação os meios para que ele possa situarse na pluralidade de estudos da linguagem e seja capaz de produzir reflexões de forma a dar suporte às exigências relativas ao estágio atual dos estudos nessa área, o que pode ser feito por meio de atividades que permitam construir um corpo de conhecimentos configurado através dos estudos que exploram a dimensão estruturante da linguagem, em seus diversos níveis (REINALDO, 2001).

No caso da reflexão sobre a escrita, impõe-se ao professor de língua materna conhecer a evolução dos estudos lingüísticos sobre o processo de escrever, os quais têm modificado antigos conceitos, ocasionando mudanças nas formas de se pensar o ensino-aprendizagem da escrita, intimamente relacionadas com as formas de se conceber a língua. Nesse campo, a concepção de língua como código e estrutura, presente nos estudos até a década de 60 do século XX, considerou a escrita como representação da fala. Em decorrência, o ato de escrever foi concebido como uma questão apenas de transformação de um código em outro, 
e a sentença/estrutura, fora do seu contexto de uso, foi escolhida como unidade principal de observação.

A partir da década de 80, o tópico da escrita passou a ser abordado sob diferentes perspectivas. Uma delas é a do texto como processo, cujo foco, nos primeiros estudos, foram os fatores cognitivos envolvidos na produção, como planejamento e revisão (FLOWER e HAYES, 1987), ampliando, posteriormente, para os fatores sociocognitivos, como fato/ realidade, história discursiva individual, discursos institucionais, parâmetros de textualização (MEURER, 1997). A principal contribuição dessa perspectiva teórica para o ensino-aprendizagem da escrita foi a de que o ato de escrever envolve, além do conhecimento do código lingüístico, outros conhecimentos que devem ser disponibilizados ao aprendiz, juntamente com as habilidades de planejar e revisar texto.

Outra perspectiva, presente nos estudos das duas últimas décadas, é a do texto como produto, que enfocou, inicialmente, a textualidade, nas dimensões formal, semântico-conceituale pragmática, fornecendo novos parâmetros para a avaliação de um texto escrito (BEAUGRANDE e DRESSLER, 1981; KOCH, 1986; VAL, 1993). No momento seguinte, início da década de 90, os estudos passaram a explorar o tópico da tipologia textual, sob o argumento de que uma das diferenças básicas entre as línguas reside nas formas de textualização e, em particular, na forma como os gêneros textuais atuam na sociedade ao representarem a cultura em formas textuais (MARCUSCHI, 2000).

A concepção de que os gêneros textuais representam a sedimentação de práticas sociais tem levado os estudiosos da Didática de Línguas, como Schneuwly e Dolz ( 1999), a defenderem a presença dos gêneros textuais na escola como uma forma de favorecer o desenvolvimento da competência textual e discursiva do alunado: por meio desse instrumento pode-se estabelecer, no âmbito do ensino da produção de texto, a articulação entre as práticas sociais e os objetos escolares de aprendizagem. Embora essa forma de pensar o ensinoaprendizagem da escrita já circule em alguns materiais didáticos, sua introdução nos cursos de formação ainda não se deu de forma efetiva. O desafio atual é a socialização desse saber entre professores da educação básica, via formação inicial e/ou continuada.

Outro saber conceitual inerente à formação do professor de língua diz respeito à avaliação, dado o indispensável envolvimento 
desse profissional com esse componente do ensino. A avaliação como prática educativa surgiu por volta do século XVII, e constitui, até hoje, um componente de natureza complexa que pode se definido, em sentido amplo, como um julgamento de valor sobre dados, tendo em vista uma tomada de decisão. Duas concepções teóricas de avaliação nas práticas educativas são reconhecidas na bibliografia sobre o tema: a avaliação classificatória ou seletiva, cujo objetivo é atestar a competência acerca da formação do indivíduo, conferindo-lhe ou não a certificação pela aquisição do conteúdo programático; e a avaliação formativa, cujo objetivo é regular o acompanhamento dos avanços do aluno, permitindo-lhe uma ação pedagógica diferenciada, constituindo-se, por essa razão, um instrumento contra o fracasso escolar (PERRENOUD, 1999). O saber construído sobre a escrita nos moldes acima referidos trouxe mudanças significativas nos parâmetros da avaliação classificatória de textos, bem como nos procedimentos da avaliação formativa com vistas à aprendizagem de textos, que passaram a ser definidos pelos princípios enunciativos que regem as relações autor-texto, leitor-texto, as especificidades dos diversos gêneros e suportes de texto, bem como dos fatores de textualidade.

Já os saberes integradores, que representam o segundo componente na formação do professor, são relativos ao ensino dos conteúdos escolares e oriundos das pesquisas realizadas na área de ensino do conteúdo específico. No processo de formação, esses saberes são construídos por meio de atividades desequilibradoras, em que o professor é conduzido a tomar consciência de questões envolvidas no ensino-aprendizagem do conteúdo específico, inclusive as relacionadas aos acontecimentos da sala de aula. Com tais atividades, pretende-se envolver o professor na reflexão crítica sobre as ações de ensino, e leválo a considerar a sala de aula como o espaço de busca do conhecimento e não como lugar da certeza, ou de aplicação de um conhecimento pronto. No caso da formação do professor de língua materna, tornase relevante o desenvolvimento da habilidade de ensino e o conhecimento de pesquisa sobre ensino-aprendizagem na área de linguagem. Aplicados a situações de ensino e avaliação da escrita, esses saberes, por revelarem a(s) concepção(ões) subjacente(s) à(s) prática(s) do professor em formação, podem constituir-se um instrumento de reelaboração dessa(s) concepção(ões) e prática(s). 
A questão do modo de utilização desses saberes está relacionada a dois modelos de formação, conhecidos na bibliografia especializada pelas seguintes designações:

a) racionalidade técnica, modelo em que a teoria e a prática são apresentadas, de forma dicotômica, ao profissional em formação. De acordo com esse modelo, a atualização profissional se dá pela justaposição entre formação inicial e aperfeiçoamento centrado na revisão de velhas concepções teóricas, apresentadas, mais uma vez, de forma distanciada da prática;

b) reflexividade, modelo que objetiva favorecer, ao lado do saber conceitual e metodológico, situações nas quais o professor em formação tenha oportunidade de refletir sobre o processo de ensinoaprendizagem, o que, a nosso ver, representa a construção do saber integrador, nos termos acima assinalados. No caso da formação continuada, esse modelo possibilita ao professor repensar a prática e seus conceitos subjacentes, visando à construção de novos significados para ela (MAGALHÃES 2001; PERRENOUD, 2002).

Essa construção, no entender de Perrenoud, só ocorre quando se contempla o trabalho com as crenças e expectativas cognitivas, sociais e afetivas, através das quais o professor em formação processa os saberes conceituais a ele apresentados. Isso porque, na visão desse autor, a ação de ensino passa por aquilo que, no indivíduo, garante uma certa permanência das formas de pensar, de estar no mundo, de avaliar a situação, de agir. Desse modo, a formação continuada deve remeter ao que está subjacente à ação docente, em particular aos saberes conceituais, aos saberes integradores, às atitudes.

Nessa linha de reflexão, Perrenoud (2002) esboça um procedimento de formação que opera de forma explícita e direta com o habitus profissional, especialmente com seus componentes menos conscientes. A noção de habitusé utilizada pelo autor, seguindo Bourdieu ([1972]1999), para designar o conjunto dos esquemas de que um indivíduo dispõe em um determinado momento de sua vida. Por se tratar de um conjunto de disposições interiorizadas, apreendemos apenas suas manifestações através dos atos e das formas de inserção no mundo. Defende o autor que o sentido de um trabalho sobre o habitus surge apenas quando a ação pretende ser racional e afirma-se como a aplicação de saberes e de princípios legítimos. Nessa situação, a regulação racional aparentemente 
não exige tomada de consciência sobre os esquemas do profissional, mas um reexame crítico do saber conceitual ou metodológico que fundamenta sua ação, levando-o a desativar os esquemas atuais, procedimento de formação que demanda muito tempo. Isso explica a importância da identificação dos pontos de vista do professor sobre o seu objeto de ensino como uma atividade de formação continuada.

O presente trabalho, portanto, procura se inserir na perspectiva de formação continuada que prioriza a análise da prática, em que os professores participantes são levados a refletir sobre sua relação com o saber sobre escrita e avaliação da escrita, o que é evidenciado no seu modo de avaliar os textos escolares escritos.

\section{O contexto de formação continuada e o instrumento de coleta dos dados}

O contexto de formação continuada em foco é o de um curso de especialização. Trata-se de um contexto em que o professor busca, ao mesmo tempo, aperfeiçoamento e incentivo para sua carreira profissional, constituindo-se, na realidade brasileira, um dos espaços mais viáveis para a prática da reflexão por mais tempo, o que pode proporcionar ao aluno-professor, por meio das disciplinas, um crescimento profissional de qualidade (MAGALHÃES, 2001).

De caráter presencial, o Curso de Especialização em Lingüística Aplicada ao Ensino de Língua Portuguesa, da Universidade Federal de Campina Grande, na versão aqui referida, foi organizado com 360 horas-aula distribuídas em 8 disciplinas ${ }^{2}$ que procuraram fundamentar, ao mesmo tempo, o saber conceitual sobre língua e o saber integrador relacionado com o ensino de língua materna, de acordo com as contribuições mais recentes das ciências da linguagem.

Os dados empíricos aqui analisados foram coletados na disciplina Avaliação e Preparação de Material Didático ( 45 horas-aula), em dezembro de 2002, na qual os participantes realizaram a leitura dos

\footnotetext{
${ }^{2}$ Integraram a estrutura curricular do Curso as seguintes disciplinas: Tópicos de Sociolingüística, Tópicos de Lingüística Textual, Metodologia da Pesquisa Aplicada ao Ensino de Língua, Teoria e Prática de Escrita, Tópicos de Gramática, Análise e Preparação de Material Didático.
} 
seguintes textos sobre avaliação: "A avaliação entre duas lógicas" (PERRENOUD, 1999), "Avaliação" (SERAFINI, 1989) e "Os destinos da avaliação no manual do professor" (MARCUSCHI, 2001).

A disciplina foi antecedida pela disciplina Teoria e Prática de Escrita ( 45 horas-aula), durante a qual foram lidos os seguintes textos sobre escrita: "Esboço de um modelo de produção de texto" (MEURER, 1997); "Gêneros textuais: definição e funcionalidade" (MARCUSCHI, 2002) e "Os gêneros escolares: das práticas de linguagem aos objetos escolares" (SCHNEUWLY e DOLZ, 1999). Sobre o tópico avaliação de textos escritos, a referência central foi o livro "Professor-leitor aluno-autor: reflexões sobre avaliação do texto escolar" (EVANGELISTA et alii, 1998).

Com o objetivo de gerar dados que revelassem a mobilização dos conceitos de escrita e avaliação de texto, apresentados nas disciplinas já referidas, utilizou-se como instrumento uma atividade de correção /avaliação de um texto escolar, acompanhada de justificativa escrita para a atribuição da nota pelos sujeitos, conforme a instrução:

Leia a redação abaixo, escrita por um aluno da $6^{\underline{a}}$ série do Ensino Fundamental, corrija-a e atribua-lhe uma nota. Diga e explique em que você está se baseando para fazer essa correção.

A redação em referência foi produzida em sala de aula de uma escola da rede privada, em situação de avaliação bimestral, e foi orientada pelo seguinte enunciado:

Redija uma pequena notícia com a seguinte manchete: ALÔ VOCÊ: NOVAS ATRAÇÕES NO MAIOR CARNAVAL FORA DE ÉPOCA Obs. Lembre-se das três partes que compõem uma notícia. A manchete você já tem, crie o lide e o corpo da notícia ( mínimo 6 linhas).

Em atendimento a essa solicitação, o aluno escreveu o seguinte texto:

1. O bloco Alô Você vai trazerpara Campina Grande varias atraçôes como a banda
2. Araketo, Fernando Vanuci e muitas outras. Vai sair na Quinta-feira, começa no
3. SPAZZIO e termina no PARQUE DO POVO onde a folia vai estar solta.
4. A precisam da prefeitura foi construir esse bloco pois muitas pessoas famosas
5. vinheram para eles ficarem juntos construíram o bloco que ai o trouxeramo
6. Araketo e fizeram o bloco que vocês vem.
7. ALÔ VOCÊ
8. FIM


Entendemos que a atividade solicitada às professoras pode ser considerada um procedimento de formação reflexiva, de natureza desequilibradora, nos termos aqui assinalados: por um lado, ao contemplar a ação de ensino - avaliar -, leva o professor a manifestar as crenças e esquemas que orientam suas habituais ações de avaliação de textos (aspectos ortográficos e morfossintáticos, por exemplo); por outro lado, ao solicitar uma justificativa inspirada em um saber conceitual que lhe foi apresentado, conduz esse professor a manifestar a sua forma de processar esse novo saber na prática profissional. Nesse sentido, um saber que devia ser manifestado, na avaliação do texto em referência, era o de que ele representa uma situação de mudança do gênero redação escolar para o gênero notícia. Com essa visão, impunha-se a consideração, por exemplo, da estrutura composicional do segundo gênero como critério relevante de avaliação.

Nessa perspectiva, analisamos, a seguir, o modo como o saber conceitual sobre escrita e avaliação de texto foi mobilizado por três professoras participantes do Curso (P1, P2, P3), selecionadas dentre sete que realizaram a tarefa, por terem a mesma formação de origem e o mesmo tempo de experiência: licenciatura em Letras na mesma instituição e atuação por cinco anos no ensino fundamental e médio.

\section{Os saberes mobilizados pelas professoras na prática de avaliação do texto}

A observação do material coletado (textos corrigidos com atribuição de nota acompanhada de uma justificativa) permitiu-nos constatar que, na especificação do que avaliar e de como avaliar o texto escrito, as professoras selecionadas revelaram formas diferenciadas de mobilização dos saberes sobre escrita e avaliação de texto a elas disponibilizados nas disciplinas referidas. Essa diferenciação, a nosso ver, é reveladora dos diferentes efeitos que um procedimento de formação pode ter sobre o conjunto de crenças e conhecimentos de profissionais em formação continuada. Assim, embora, teoricamente, tenham passado a saber o que deve e o que não deve ser feito, encontram como principal obstáculo o saber fazer: o como integrar o saber conceitual recém-adquirido à nova prática de avaliação de texto.

Esse quadro de diferentes efeitos do procedimento adotado sobre a relação entre concepção e execução explica o fato de uma professora 
(P1), na demonstração do saber fazer, ter preferido permanecer na situação de estabilidade, adotando uma avaliação prioritariamente orientada pelos critérios que remetem à concepção de escrita como código, conhecimento que provavelmente embasou sua formação inicial e sua prática docente durante cinco anos. Esse dado evidencia que a ação docente é marcada por aquilo que, nos termos de Perrenoud, garante, no professor, fixidez do seu modo de pensar e agir. A desativação dos esquemas que orientam suas rotinas, por representar risco, demandaria tempo de experiência sob a nova orientação teórica. Essa é a razão por que P1, em sua justificativa para atribuição da nota 7.0 (saber integrador), mobiliza, quase exclusivamente, o saber conceitual que já detinha, o que pode ser depreendido da leitura de (1):

O texto apresenta, no primeiro parágrafo, o nome da cidade onde ocorrerá o evento, o nome do bloco, atrações, o local de concentração, o lugar onde termina a festa e ressalta que as pessoas vão se divertir. Há a necessidade de acentuar a palavra "vários", faltou destacar o $2^{\circ}$ nome do bloco em inicial maiúscula"Alô Você". O dia da semana, "quinta-feira", deve estar escrito em inicial minúscula porque é substantivo simples. A modificação sugerida foi trocar "começa"por "a concentração é”. Uma notícia de jornal precisa ter clareza de idéias e informações. Nota -5.0

Quanto ao segundo parágrafo, eu pediria para o aluno reescrever porque as informações ficaram confusas. Eu explicaria que a prefeitura promove a festa, os empresários criam os blocos e as pessoas compram abadás. A partir dessas informações, eu iria sugerir que o aluno refletisse e procurasse modificar o parágrafo. Nota: 2.0 Nota final: $5+2=7.0$ (P1)

Observa-se, nessa justificativa, que a segmentação linear do processo de avaliação correspondente ao número de parágrafos do texto corrigido (5.0 para o primeiro parágrafo e 2.0 para o segundo) parece sinalizar que a lógica para a atribuição da nota por P1 é apenas a da quantidade de erros assinalados no plano da convenção do sistema gráfico (Há a necessidade de acentuar a palavra "vários, faltou destacar o 2 nome do bloco em inicial maiúscula" Alô Você". O dia da semana, "quinta-feira" deve estar escrito em inicial minúscula porque é substantivo simples), ou no plano da morfossintaxe da escrita padrão ( A modificação sugerida foi trocar "começa" por "a concentração é"). A referência à necessidade de explicitação do sentido, no âmbito dos 
constituintes do enunciado, constitui o único critério evocado para referir à noção de gênero (Uma notícia de jornal precisa ter clareza de idéias e informações), desconsiderando componentes, como a estrutura composicional, já lembrada na instrução da tarefa (crie o lide e o corpo da notícia). Embora sinalize a preocupação com a prática da reescritura, procedimento associado à concepção de avaliação como processo de aprendizagem e de escrita como processo sociocognitivo que envolve reelaboração, $\mathrm{P} 1$ se atém apenas a aspectos da higienização verbal dos enunciados (Quanto ao segundo parágrafo, eu pediria para o aluno reescrever porque as informações ficaram confusas ).

Por outro lado, duas professoras (P2 e P3), na demonstração do saber avaliar texto, preferiram assumir a situação de instabilidade, ao incluírem, ainda que sem o domínio de alguns conceitos apresentados no curso, critérios de base textual, como se pode observar na leitura de (2):

Observando o texto, vemos que este possui algumas inadequações gramaticais como: acentuação, marcas da oralidade, problemas de construção frasal e outros. Porém, o aluno atendeu a solicitação da proposta de redação, organizando seu texto, utilizando características estruturais desse gênero. Como também, apresentou através do conteúdo da redação que ele entende que informações deve compor a notícia. Desta forma, a nota atribuída (7.0) é coerente com a observação feita entre a forma e o conteúdo, dando ênfase ao conteúdo apresentado na redação. Diante disso, os critérios de avaliação que prevaleceram foi a habilidade de produzir um texto desse gênero, como também o aspecto formal da língua. (P2)

Nessa demonstração do saber integrador - avaliar texto -, P2 procura inserir, com algumas simplificações, elementos do saber conceitual recém - adquirido. Um deles é a referência ao componente estrutura composicional, presente na teoria de gênero (as características estruturais do gênero notícia), embora não atente ainda para o fato de que a estrutura do texto do aluno se apresenta mais próxima da redação escolar do que do gênero solicitado (ver a expressão de fechamento $A L \hat{O}$ VOCÊ FIM). Dois outros elementos constitutivos do gênero parecem não assumir ainda relevância na avaliação realizada por P2: o conteúdo, que, embora seja evocado, é referido de forma breve, até pacífica (Como também, apresentou através do conteúdo da redação 
que ele entende que informações deve compor a notícia) e os parâmetros da situação comunicativa do texto, pois não há referência ao uso pelo aluno da linguagem implicada, típica da interação face a face (fizeram o bloco que vocês vem), em lugar da linguagem autônoma, própria da escrita jornalística.

Outro saber conceitual, manifestado de forma superficial na demonstração do saber avaliar texto, é o referente à relação fala/escrita. A inclusão da referência às "marcas da oralidade", sem especificação do caráter informal do registro, para referir à inadequação do marcador "a1́" no texto do aluno, sugere um tratamento dicotômico da relação entre as modalidades da língua, em que oralidade e escrita estão associadas, respectivamente, a informalidade e formalidade do registro. Este saber desconsidera, pois, as noções de variação e adequação, no contínuo formal - informal, no contexto dos gêneros textuais.

Outra evidência da situação de transição de P2, quanto ao processamento do saber conceitual que lhe foi apresentado nas disciplinas do Curso, manifesta-se na sobreposição de conceitos, decorrente do recurso a termos como "gênero" e "aspecto formal da língua”, oriundos de enfoques teóricos diferentes (RAFAEL, 2001). Nesse sentido, a asserção os critérios de avaliação que prevaleceram fo $i$ a habilidade de produzir um texto desse gênero, como também o aspecto formal da lingua desconsidera o conhecimento, veiculado nas obras de divulgação da Lingüística Textual, de que o gênero é uma forma comunicativa padronizada, o que significa dizer que a propriedade formal lhe é inerente. Nesse contexto, a expressão aspecto formal da língua, evocada por P2, ainda remete ao componente sistêmico, independente do gênero.

Essa situação de transição também está presente na justificativa de P3, para quem as inadequações de ordem formal, entendidas como não observação das convenções do sistema escrito (acentuação e pontuação), são também evocadas, ao lado da falta de critérios de textualidade, como atesta (3):

Apesar das informações apresentadas sobre o que foi solicitado no enunciado da proposta de atividade, o texto contém algumas inadequações com relação ao aspecto formal (acentuação e pontuação) como também, não apresenta clareza e articulação de algumas idéias, 
principalmente, no corpo da notícia, já que o aluno não organiza as informações de forma que favoreça uma compreensão. Dessa forma, a nota (6.0) atribuída ao texto, justifica-se pelas informações e pelo texto corresponder ao que foi solicitado, mas também a falta de coesão (articulação das idéias). (P3)

A orientação argumentativa desta justificativa chama atenção para a incorporação de critérios de textualidade (não apresenta clareza e articulação de algumas idéias, principalmente, no corpo da notícia, já que o aluno não organiza as informações de forma que favoreça uma compreensão), ao lado dos critérios relativos às convenções do sistema de escrita - aspecto formal (acentuação e pontuação). Entretanto, observa-se certa indefinição quanto à valoração dos critérios evocados na atribuição da nota ( a nota (6.0) atribuída ao texto, justifica-se pelas informações e pelo texto corresponder ao que foi solicitado, mas também a falta de coesão), o que se deve, em parte, à sobreposição de termos advindos da Lingüística de Texto, como o termo coesão, que está definido como articulação das idéias, quando nos estudos de texto, essa expressão, via de regra, remete ao componente semântico, campo da coerência.

Em que pese a restrição do instrumento a apenas uma atividade escrita, as diferentes formas de manifestação do saber avaliar texto, aqui descritas, evidenciam diferentes estágios de processamento pelos sujeitos dos conceitos de escrita, texto e avaliação e, em conseqüência, as diferentes disposições para alterar os parâmetros que orientam sua rotina de avaliação do texto escolar.

\section{Considerações finais}

A análise dos dados, obtidos na atividade de formação selecionada, permitiu-nos constatar que:

- o aspecto formal, como convenção do sistema escrito, parece ocupar o lugar de maior peso na prática da avaliação de texto dos sujeitos pesquisados, em que pese a mudança no seu discurso, ao evocarem os fatores de textualidade e a especificidade enunciativa da escrita, presentes no enfoque do gênero textual;

- a introdução de novos elementos conceituais como critérios de avaliação de texto, por representar desestabilização na rotina desses 
sujeitos, só é registrada naqueles que fazem a opção pela tentativa de alterar sua prática profissional.

Sem deixar de reconhecer as limitações dos dados analisados, a importância dessas constatações reside no fato de representarem pontos de vista dos sujeitos sobre o objeto de ensino enfocado avaliação de texto. Nesse sentido, os dados revelam ainda descompasso entre o discurso do professor em formação continuada, que passa a acreditar em um novo saber conceitual, e a sua prática, que tende a não apresentar alteração significativa. Apontam, por conseguinte, para a necessidade da realização de sessões reflexivas, nas quais os sujeitos analisem as limitações ou avanços do saber conceitual ou metodológico que fundamenta o seu saber avaliar texto. Entendemos que só a realização sistemática desse procedimento formativo poderá favorecer a reelaboração desses dois saberes, o que reforça a hipótese de que o contexto da especialização se apresenta como viável para se promover um crescimento profissional de qualidade.

\section{Referências Bibliográficas}

BEAUGRANDE, R.; DRESSLER, W. Introduction to Textlinguistics. Londres/ New York: Longman, 1981.

BOURDIEU, P. Outline of a theory of practice, 14 printing. Cambridge: Cambridge University Press, [1972] 1999.

CARVAlHO, A.; PEREZ, G. O saber e o saber fazer dos professores. In: Castro, Amélia e Carvalho, Anna M. Passos. (Org.). Ensinar a ensinar. São Paulo: Pioneira, 2002. p.107-124.

EVANGELISTA, A .A. et alii. Professor-Leitor Aluno-Autor: Reflexões sobre avaliação do texto escolar. Belo Horizonte: CEALE/Formato, 1998.

FLOWER, L.; HAYES, J. The dynamics of composing: making plans and juggling constraints. In: GREGG, L. Steinberg (Org.). Cognitive processes in writing. Hillsdate: New Jersey: Lawrence Erlbaum Associates.

GERALDI, J. W. Escrita, uso da escrita e avaliação. In: . (Org.). O texto na sala de aula. Cascavel: ASSOESTE, 1984.

GERALDI, J. W. Portos de passagem. São Paulo: Martins Fontes, 1993.

KOCH, I. V. Coesão textual. São Paulo: Contexto, 1986. 
MAGALHÃES, L. M. Modelos de formação continuada: os diferentes sentidos da formação reflexiva do professor. In: KLEIMAN, A. B. (Org.). A formação do professor. Campinas: Mercado de Letras, 2001, p.239-260.

MARCUSCHI, L. A. Gêneros textuais: definição e funcionalidade. In: DIONÍSIO, P. A., BEZERRA, M. A. Gêneros textuais e ensino. Rio de Janeiro: Lucerna, 2002.

MARCUSCHI, E. Os destinos da avaliação no manual do professor. In: DIONÍSIO, A . P.; BEZERRA, M. A. (Org.). O livro didático de português: múltiplos olhares. Rio de Janeiro: Lucerna, 2001, p.139-150.

MEURER, J. L. Esboço de um modelo de produção de textos. In: e Motta Roth (Org.) Parâmetros de textualização. Santa Maria: UFSM, 1997. p.13-28.

PERRENOUD, P. Avaliação: da excelência à regulação das aprendizagens. Porto Alegre: Artmed, 1999.

PERRENOUD, P. A prática reflexiva no ofício do professor. Porto Alegre: Artmed, 2002.

RAFAEL, E. L. Atualização de saberes lingüísticos de formação em sala de aula: os efeitos da transposição didática. In: KLEIMAN, A. B. (Org.). $A$ formação do professor: perspectivas da lingüistica aplicada. Campinas: Mercado de Letras, 2001. p.157-180.

REINALDO, M. A. G. M. Teoria e prática na formação do professor. Boletim da ABRALIN, v.26, número especial, I, p.163-165, 2001.

SCHNEUWLY, B.; DOLZ, J. Os gêneros escolares: das práticas de linguagem aos objetos escolares. Revista Brasileira de Educação, São Paulo, n. 11, p.5-6, 1999 .

SERAFINI, M. T. Como escrever textos. Rio de Janeiro: Globo, 1989. p.107-45.

TARDIF, Maurice. Saberes docentes \& formação profissional. Rio de Janeiro: Vozes, 2002.

VAL, M. G. C. Redação e textualidade. São Paulo: Martins Fontes, 1993. 